UDC 669.14

Author: KUZEEV Iskander Rustemovich, Doctor of Engineering, Professor, Head of the Department «Technological Machines and Equipment», Ufa State Petroleum Technological University; Kosmonavtov St., 1, Ufa, Bashkortostan Republic, Russia, 450062, kuzeev2002@mail.ru; Author: POPOVA Svetlana Vladimirovna, Ph.D., Associate Professor of the Department «Technological Machines and Equipment», Ufa State Petroleum Technological University; Kosmonavtov st. 1, Ufa, Russia, 450062;

Author: ABYZGILDINA Sakina Shagadatovna, Ph.D., Associate Professor of the Department «Technological Machines and Equipment», Ufa State Petroleum Technological University; Kosmonavtov st. 1, Ufa, Russia, 450062, svetpv2007@ya.ru

\title{
PRODUCTION OF METAL FULLERENE SURFACE LAYER FROM VARIOUS MEDIA IN THE PROCESS OF STEEL CARBONIZATION
}

\section{Extended Abstract:}

Studies devoted to production of metal fullerene layer in steels when introducing carbon from organic and inorganic media were performed. Barium carbonate was used as an inorganic medium and petroleum pitch was used as an organic medium. In order to generate the required amount of fullerenes in the process of steel samples carbonization, optimal temperature mode was found. The higher temperature, absorption and cohesive effects become less important and polymeric carbon structures destruction processes become more important. On the bottom the temperature is limited by petroleum pitch softening temperature and its transition to low-viscous state in order to enhance molecular mobility and improve the possibility of their diffusion to metal surface. Identification of fullerenes in the surface modified layer was carried out following the methods of IR-Fourier spectrometry and high-performance liquid chromatography. It was found out that nanocarbon structures, formed during carbonization in barium carbonate and petroleum pitch mediums, possess different morphology. In the process of metal carbonization from carbonates medium, the main role in fullerenes synthesis is belonged to catalytic effect of surface with generation of endohedral derivatives in the surface layer; but in the process of carbonization from pitch medium fullerenes are formed during crystallization of the latter and crystallization centers are of fullerene type. Based on theoretical data and data 
of spectral and chromatographic analysis, optimal conditions of metal fullerene layer formation in barium carbonate and petroleum pitch mediums were determined. Low cohesion of layer, modified in barium carbonate medium, with metal basis was discovered. That was caused by limited carbon diffusion in the volume of $\alpha$-Fe. According to the detected mechanism of fullerenes formation on steel surface in gaseous medium, fullerenes are formed on catalytic centers - ferrum atoms, forming thin metal fullerene layer with low defectiveness. Complex studies of carbon diffusion to steel from organic and inorganic media showed that difference between the mechanisms of metal fullerene layer formation makes it possible to develop efficient algorithms of surface modification technology.

Keywords: fullerenes, pitch, barium carbonate, liquid chromatography, modified layer.

DOI: dx.doi.org/10.15828/2075-8545-2018-10-2-135-152

MACHINE-READABLE INFORMATION ON CC-LICENSES (HTML-CODE) IN METADATA OF THE PAPER

$<$ a rel="license" href="http://creativecommons.org/licenses/by/4.0/" $><$ img alt="Creative Commons License" style="borderwidth:0" src="https://i.creativecommons.org/l/by/4.0/88x31.png" $/></ \mathrm{a}><$ br $/><$ span xmlns:dct="http://purl.org/dc/ terms/" href="http://purl.org/dc/dcmitype/Text" property="dct:title" rel="dct:type" $>$ Production of metal fullerene surface layer from various media in the process of steel carbonization. $</$ span $>$ by $<$ a xmlns:cc="http://creativecommons.org/ns\#" href="Nanotehnologii v stroitel'stve = Nanotechnologies in Construction. 2018, Vol. 10, no. 2, pp. 135- 152. DOI: dx.doi. org/10.15828/2075-8545-2018-10-2-135-152. (In Russian)." property="cc:attributionName" rel="cc:attributionURL" $>$ Kuzeev I.R, Popova S.V., Abyzgildina S.Sh. $</ a>$ is licensed under a $<$ a rel="license" href="http://creativecommons.org/licenses/ by $/ 4.0 / ">$ Creative Commons Attribution 4.0 International License $</ \mathrm{a}>.<$ br $/>$ Based on a work at $<$ a xmlns:dct="http:// purl.org/dc/terms/" href=" http://nanobuild.ru/en_EN/nanobuild-2-2018/" rel="dct:source"> http://nanobuild.ru/ en_EN/nanobuild-2-2018/</a $>$. $<$ br $/>$ Permissions beyond the scope of this license may be available at $<$ a xmlns:cc="http: $/ /$ creativecommons.org/ns\#" href="kuzeev2002@mail.ru" rel="cc:morePermissions"> kuzeev2002@mail.ru</a>.

\section{References:}

1. Chirkova A.G., Hayerlanamova E.A., Kuzeev I.R. Obrazovanie kvazimnogoslojnyh obolochek pri jekspluatacii trub zmeevika pechi piroliza uglevodorodov [Formation of quasimultilayered covers at operation of pipes of a coil of the furnace of pyrolysis of hydrocarbons]. Mehanika kompozicionnyh materialov i konstrukcij [Mechanics of composite materials and designs]. 2004. Volume 10. No. 2. p. 153-165. (In Russian).

2. Kuzeev I.R., Popova S.V., Fazlyakhmetov R.F. Wear resistance of steel 20 after thermochemical treatment in fluid petroleum pitch. Journal of Friction and Wear. 2011. Vol. 32. № 3. p. 186-191. 
3. Gabdullina M. R., Kuzeev I.R., Nikiforova D.K., Gabdullin M.F. Formirovanie metallofullerenovogo poverhnostnogo sloja s cel'ju passivacii poverhnosti v uglerodnyh staljah [Formation of a metalfullerene blanket for the purpose of passivation of a surface in carbon the steel]. The electronic scientific journal «Oil and gas business». 2014. No. 3. p. 310-328. (In Russian).

4. Stepanyuk O.V. Teoreticheskoe issledovanie processov formirovanija i fizicheskih svojstv nanosturuktur na poverhnosti [A theoretical research of processes of formation and physical properties nanostructure on a surface]. Ph.D. thesis. Moscow, 2010. 25 p. (In Russian).

5. Zolotukhin A.A. Formirovanie uglerodnyh plenok iz gazovoj fazy [Formation of carbon films from a gas phase]. Doctorate Thesis. Moscow, 2007. 25 p. (In Russian).

6. Korneeva Yu.V. Strukturnye prevrashhenija v metallicheskih chasticah katalizatorov $\mathrm{v}$ razlichnyh processah sinteza UNT [Structural transformations in metal particles of catalysts in various processes of synthesis of UNT]. Ph.D. Thesis. Moscow, 2008. 22 p. (In Russian).

7. Mutigullin I.V. Osobennosti vzaimodejstvija atomov ugleroda na poverhnosti i v ob'eme monokristallov $\mathrm{Fe}, \mathrm{Ni}$ i splavov na ih osnove [Features of interaction of atoms of carbon on a surface and in volume of monocrystals of Fe, Ni and alloys on their basis]. Ph.D. Thesis. Moscow, 2010. 23 p. (In Russian).

8. Arzamasov B.N. Spravochnik po konstrukcionnym materialam [Reference book on constructional materials]. Moscow: MSTU of N.E. Bauman, 2005. 640 p. (In Russian).

9. Kiselyova T.Yu., Novikova A.A., Tarasov B.P., Muradyan B.C., Volodin A.A. Diagnostika produktov jelektrodugovogo sinteza uglerodnyh nanotrubok na katalizatorah $\mathrm{Fe}$ i $\mathrm{Fe}-\mathrm{Ni}$ metodom messbaujerovskoj spektroskopii [Diagnostics of products of arc synthesis of carbon nanotubes on $\mathrm{Fe}$ and $\mathrm{Fe}-\mathrm{Ni}$ catalysts by method of messbauerovsky spectroscopy]. In Proc. of theb1st International conference «Carbon: fundamental problems of science, materials science, technology». Moscow, 2002. P. 110. (In Russian).

10. Kudashov A.G., Okotrub L.V., Yudanov I.F., Guselnikov L.V., Abrosimov O.T., Choubin Yu.V. Kataliticheskij sintez uglerodnyh nanotrubok [Catalytic synthesis of carbon nanopipes]. In Proc. of the 1st International conference «Carbon: fundamental problems of science, materials science, technology». Moscow, 2002. P. 124. (In Russian).

11. Shchur D.V., Matysina Z.A., Zaginaychenko S. Yu. Vzaimodejstvie uglerod - katalizator pri sinteze uglerodnyh nanotrubok [Interaction carbon - the catalyst at synthesis of carbon nanotubes]. In Proc. of the1st International conference «Carbon: fundamental problems of science, materials science, technology». Moscow, 2002. P. 141. (In Russian).

12. Karayeva A.R., Dolgova E.A., Kharitonov D.N., Maslov I.A., Kamenev A.A., Tretyakov V.F., Mordkovich B.Z. Aktivnost' Ni i Fe v sinteze nanougleroda pri kataliticheskoj konversii metana [Activity of $\mathrm{Ni}$ and $\mathrm{Fe}$ in synthesis of nanocarbon at catalytic conversion of a methane]. Russian Chemical Journal. 2006. Volume L. No. 1. P. 6467. (In Russian). 
13. Kuzeev I.R., Popova S.V., Vasilyev A.N., Shemagonova E.V. Uglerod v strukture zheleznoj matricy i ego vlijanie na jekspluatacionnye svojstva konstrukcionnyh stalej [Carbon in the structure of iron matrix and its influence on the operational properties of structural steels]. Upravlenie kachestvom v neftegazovom dele [Quality Management in Oil and Gas Engineering]. 2010. № 1. p. 30-33. (In Russian).

14. Korneeva Yu.V. Strukturnye prevrashhenija v metallicheskih chasticah katalizatorov $\mathrm{v}$ razlichnyh processah sinteza uglerodnyh nanotrubok [Structural transfomations in metallics of catalysts in various processes of synthesis of carbon nanotubes]. Ph.D. Thesis. Moscow, 2008. 22 p. (In Russian).

15. Sidorov L.N., Yurovskaya M.A., Borschevsky A.Ya., et al. Fullerenes. Moscow: Publishing House «Ekzamen», 2005, 688 p. (In Russian).

16. Kuzeev I.R. Sovershenstvovanie tehnologii i povyshenie dolgovechnosti reakcionnyh apparatov termodestruktivnyh processov pererabotki uglevodorodnogo syr'ja [Perfecting of technology and increase in a longevity of reactors of the thermodestructive processes of processing of hydrocarbonic raw materials]. Doctorate Thesis. Ufa, UNI, 1987, 427 p. (In Russian).

17. Y.I.Li.Surface Geometry of C60 on Ag(111)/Y.I. Li, K. Pussi, K.J. Hanna, L.-L. Wang, D.D. Johnson, H.-P. Cheng, H. Shin, S. Curtarolo, W. Moritz, J.A. Smerdon, R. McGrath and R.D. Diehl. PHYSICAL REVIEW LETTERS PRL. 103.056101 (2009).

18. Gafarova V.A. Carbon in condensed hydrocarbon phases, steels and cast irons. Nanotehnologii v stroitel'stve $=$ Nanotechnologies in Construction. 2017, Vol. 9, no. 6, pp. 111-128. DOI: dx.doi.org/10.15828/2075-8545-2017-9-6-111-128. (In Russian).

19. Demchenko M.V., Sisanbaev A.V., Kuzeev I.R. Research of state of metal welded joint by deformation and corrosion surface projection parameters. Nanotehnologii v stroitel'stve $=$ Nanotechnologies in Construction. 2017, Vol. 9, no. 5, pp. 98-115. DOI: dx.doi.org/10.15828/2075-8545-2017-9-5-98-115. (In Russian).

20. Kuzeev I.R. Identification of fullerenes in iron-carbon alloys structure. Nanotehnologii v stroitel'stve $=$ Nanotechnologies in Construction. 2017, Vol. 9, no. 6, pp. 151163. DOI: dx.doi.org/10.15828/2075-8545-2017-9-6-151-163. (In Russian).

\section{DeAR COLleagues!}

THE REFERENCE TO THIS PAPER HAS THE FOLLOWING CITATION FORMAT:

Kuzeev I.R, Popova S.V., Abyzgildina S.Sh. Production of metal fullerene surface layer from various media in the process of steel carbonization. Nanotehnologii v stroitel'stve $=$ Nanotechnologies in Construction. 2018, Vol. 10, no. 2, pp. 135152. DOI: dx.doi.org/10.15828/2075-8545-2018-10-2-135-152. (In Russian). 
УДК 669.14

Автор: КУЗЕЕВ Искандер Рустемович, д.т.н., проф. каф. «Технологические машины и оборудование» ФГБОУ ВО «УГНТУ»; ул. Космонавтов, корп.1, г. Уфа, Россия, 450062, kuzeev2002@mail.ru;

Автор: ПОПОВА Светлана Владимировна, к.т.н., доц. каф. «Технологические машины и оборудование» ФГБОУ ВО «УГНТУ»; ул. Космонавтов, корп.1, г. Уфа, Россия, 450062;

Автор: АБЫЗГИЛЬДИНА Сакина Шагадатовна, к.т.н., доц. каф. «Технологические машины и оборудование» ФГБОУ ВО «УГНТУ»; ул. Космонавтов, корп.1, г. Уфа, Россия, 450062, sakina39@rambler.ru

\section{ПОЛУЧЕНИЕ МЕТАЛЛОФУЛЛЕРЕНОВОГО ПОВЕРХНОСТНОГО СЛОЯ ПРИ НАУГЛЕРОЖИВАНИИ СТАЛИ ИЗ РАЗЛИЧНЫХ СРЕД}

АННОТАЦИЯ К СТАТЬЕ (АВТОРСКОЕ РЕЗЮМЕ, РЕФЕРАТ):

Проведены исследования по созданию металлофуллеренового слоя в сталях при внедрении углерода из органической и неорганической сред. В качестве неорганической среды использовали карбонат бария, а в качестве органической среды использовали пек нефтяного происхождения. С целью формирования необходимого количества фуллеренов при науглероживании стальных образцов подобран оптимальный температурный режим. Чем выше температура, тем меньшую роль играют адсорбционные и когезионные эффекты и большую роль начинают играть процессы деструкции полимерных углеродных структур. Снизу температура ограничена температурой размягчения нефтяного пека и перехода его в маловязкое состояние для улучшения подвижности молекул и возможности их диффузии к поверхности металла. Идентификация фуллеренов в поверхностном модифицированном слое производилась методами ИК-Фурье спектрометрии и высокоэффективной жидкостной хроматографии. Обнаружено, что образующиеся в ходе науглероживания в среде карбоната бария и в среде пека наноуглеродные структуры имеют различную морфологию. При науглероживании из среды карбонатов металлов определяющую роль при синтезе фуллеренов играет каталитическое действие поверхности с образованием эндоэдральных производных в поверхностном слое, в то время как из среды пека фуллерены формируются при кристаллизации последнего, при этом центры кристаллизации имеют фуллереновую природу. Руководствуясь теоретическими данными и данными спектрального и хроматографического анализа, установлены оптимальные 
условия формирования металлофуллеренового слоя в среде карбоната бария и нефтяного пека. Обнаружено слабое сцепление модифицированного в среде карбоната бария слоя с металлической основой, что вызвано ограничением диффузии углерода в объем $\alpha$-Fе. Согласно выявленному механизму формирования фуллеренов в газовой среде на поверхности стали фуллерены формируются на каталитических центрах - атомах железа, образуя тонкий металлофуллереновый слой, обладающий низкой дефектностью. Комплексные исследования диффузии углерода в сталь из органической и неорганической среды показали различия механизмов формирования металлофуллеренового слоя и позволили разработать эффективные алгоритмы технологии модифицирования поверхности.

Ключевые слова: фуллерены, пек, карбонат бария, жидкостная хроматография, модифицированный слой.

DOI: dx.doi.org/10.15828/2075-8545-2018-10-2-135-152

\footnotetext{
МАШИНОЧИТАЕМАЯ ИНФОРМАЦИЯ О СС-ЛИЦЕНЗИИ В МЕТАДАННЫХ СТАТЬИ (НTML-КОД):

$<$ a rel="license" href="http://creativecommons.org/licenses/by/4.0/" ><img alt="Лицензия Creative Commons" style="borderwidth:0" src="https://i.creativecommons.org/l/by/4.0/88x31.png" $/></ \mathrm{a}><$ br $/>$ Произведение «<span xmlns:dct="http:// purl.org/dc/terms/" href="http://purl.org/dc/dcmitype/Text" property="dct:title" rel="dct:type"> Получение металлофуллерено- вого поверхностного слоя при науглероживании стали из различных сред </span $>$ » созданное автором по имени <a xmlns:cc="http://creativecommons.org/ns\#" href="Нанотехнологии в строительстве. - 2018. - Том 10, № 2. - C. $135-152$. - DOI: dx.doi.org/10.15828/2075-8545-2018-10-2-135-152." property="cc:attributionName" rel="cc:attributionURL"> Кузеeв И.Р., Попова С.В., Абызгильдина С.Ш. </a>, публикуется на условиях < a rel="license" href="http://creativecommons.org/ licenses/by/4.0/"> лицензии Creative Commons C указанием авторства 4.0 Всемирная $</ \mathrm{a}>$. $<\mathrm{br} />$ Основано на произведении c < a xmlns:dct="http://purl.org/dc/terms/" href="http://nanobuild.ru/ru_RU/nanobuild-2-2018/" rel="dct:source">http:// nanobuild.ru/ru_RU/nanobuild-2-2018/</a >.<br />Разрешения, выходящие за рамки данной лицензии, могут быть доступны на странице $<$ a xmlns:cc="http://creativecommons.org/ns\#" href="kuzeev2002@mail.ru" rel="cc:morePermissions">kuze ev2002@mail.ru</a $>$.
}

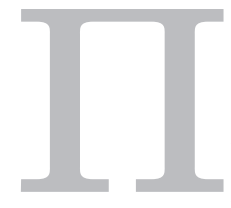

ри внедрении углерода в металл из углеводородной среды при реализации технологических процессов переработки нефти наблюдаются негативные процессы, связанные с изменением механических характеристик стали в приповерхностной зоне [1]. При этом наблюдается чешуйчатое отслаивание металла, образование трещин, потеря устойчивости формы оболочек. С другой стороны, при контролируемом внедрении углерода в поверхностные слои стали наблюдают- 
ся положительные эффекты, связанные с повышением коррозионной и эрозионной стойкости [2, 3] конструкционного материала. Поскольку показано, что процессы, приводящие к разрушению поликристаллических материалов, формируются на наноуровне [19], а фуллерены являются характерными нанообъектами, изучению характера взаимодействия фуллеренов в сталях с матрицей железа уделяется большое внимание [20].

Внедрение углерода в стали можно осуществить различными способами, связанными с тем, из какой среды углерод будет взаимодействовать с поверхностью. Нас интересуют два варианта: внедрение из органической среды, в качестве которой используется пек, и из неорганической среды, в качестве которой используется карбонат бария.

Модифицирование поверхностного слоя стальных образцов из стали 20 производилось путем насыщения их углеродом в твердом карбюризаторе и заключалось в формировании металлофуллеренового поверхностного слоя.

Науглероживание производилось в твердом карбюризаторе - в среде углекислого бария $\mathrm{BaCO}_{3}$. Известно, что металлическая поверхность оказывает каталитическое воздействие на формирование высокоупорядоченных наноуглеродных структур [4-7]. Поэтому важно знать, из какого агрегатного состояния вещества будет происходить внедрение углерода. Механизм науглероживания из карбонатов металлов формально похож на механизм науглероживания из кокса или древесного угля, протекающего через стадию образования углекислого $\left(\mathrm{CO}_{2}\right)$ или угарного (CO) газа.

Использовали следующий алгоритм подготовки образцов из стали 20: подлежащие химико-термической обработке (XТО) образцы и карбюризатор упаковывались в контейнер и нагревались в печи до температуры $480^{\circ} \mathrm{C}$ в течение 2,5 часов. Затем образцы резко охлаждали до температуры $360^{\circ} \mathrm{C}$ с целью закрепления процесса диффузии на начальной стадии нагрева и снова нагревали до $480^{\circ} \mathrm{C}$ с выдержкой 30 минут. Охлаждение происходило на воздухе. Условия термообработки подбирались из соображения стадийности процесса насыщения углеродом поверхностного слоя с учетом экспериментальных данных авторов $[4-7]$.

Анализ собственных экспериментальных данных показывает, что для образования качественного покрытия необходимо стремиться орга- 
низовать диффузию при более низких температурах процесса и не допустить включения процессов фазового перехода в стали. В то же время, необходимо обеспечить наличие атомов с достаточно высокой энергией в микрообъемах для обеспечения образования химических связей $[8,13]$.

При разработке технологии диффузионного насыщения углеродом поверхности стали учитывали результаты, приведенные в работах [7, 9-11], указывающие на то, что каталитическими центрами зарождения карбидов, которые используются далее для построения одностенных углеродных нанотрубок (УНТ), являются железо $\alpha-\mathrm{Fe}$, никель $\mathrm{Ni}$, кобальт Со и другие d-металлы.

В исследованиях [4-7, 9-12] показано, что центрами зарождения УНТ являются карбиды металлов, а процесс их образования происходит в интервале температур $600-800^{\circ} \mathrm{C}$. Показано [14], что каталитическими свойствами при синтезе наноуглерода обладают достаточно мелкие частицы $\alpha-\mathrm{Fe}$, на которой формируется карбидная оболочка, координирующая рост зарождающейся нанотрубки (рис. 1).

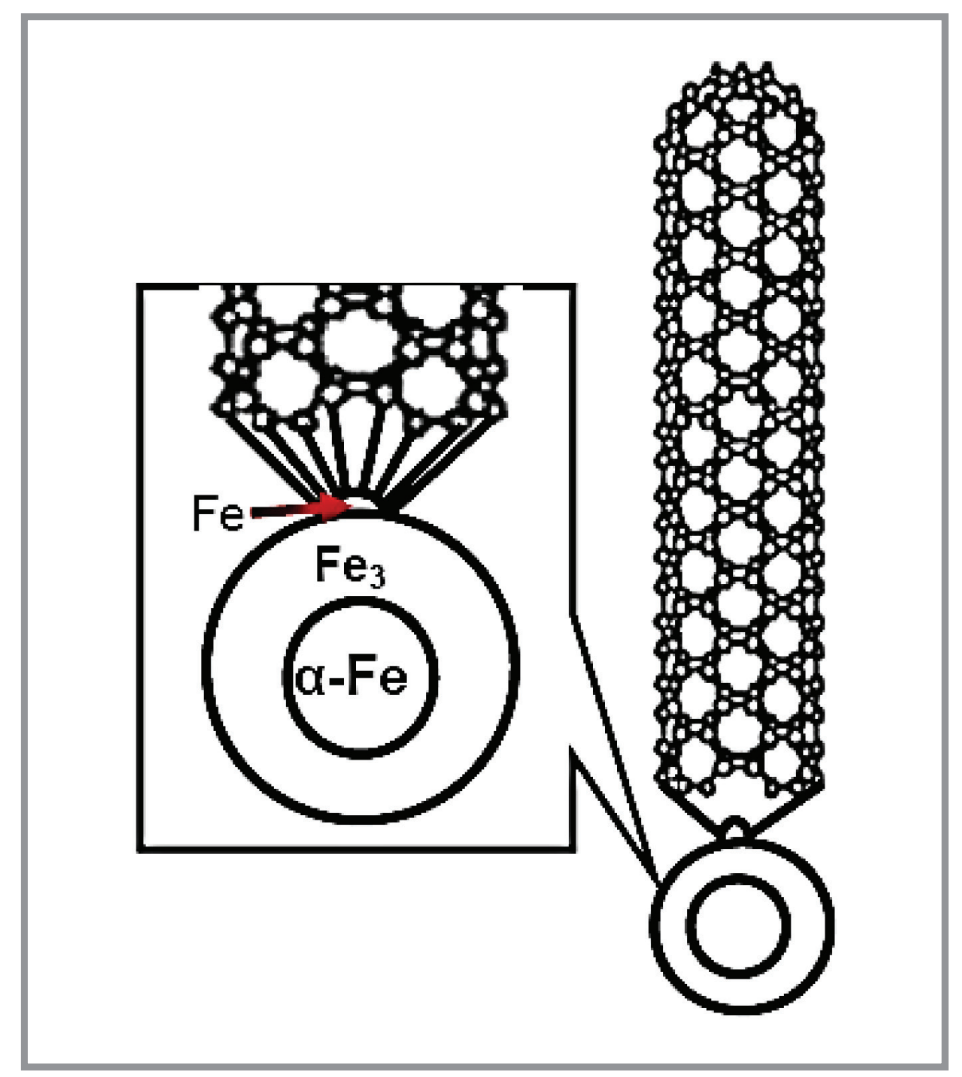

Рис. 1. Механизм роста углеродной нанотрубки [14] 
Температуру в печи необходимо ограничить $750^{\circ} \mathrm{C}$, что связано с некоторыми конкурирующими процессами образования каталитических кластеров и некаталитических частиц $\gamma$-Fe(C) [15].

Выбранная температура процесса науглероживания стальных образцов недостаточна для образования нанотрубок. Вместе с тем из-за резкого последовательного изменения температуры - с $480^{\circ} \mathrm{C}$ до $360^{\circ} \mathrm{C}$ и снова до $480^{\circ} \mathrm{C}$ - повышается энергия конденсирующихся частиц углерода, адсорбирующихся на поверхности стали, что должно привести к образованию металлофуллереновых комплексов - молекул эндоэдральных фуллеренов с атомом Fе в центре.

При образовании кокса из жидкой фазы система эволюционирует через формирование так называемой пековой фазы [16]. Пековая фаза приобретает свои свойства квазикристаллического вещества за счет иерархического структурирования парамагнитных соединений, к которым, прежде всего, следует отнести асфальтены, карбены, карбоиды.

При контакте жидкого пека с поверхностью (независимо от природы поверхности - металл, неметалл, полимер или керамика) обнаруживаются элементы, присущие кристаллическим веществам: центры кристаллизации, дислокации роста, зеренная структура. Эти структуры обнаруживаются в макромасштабе или при небольшом увеличении (рис. 2).

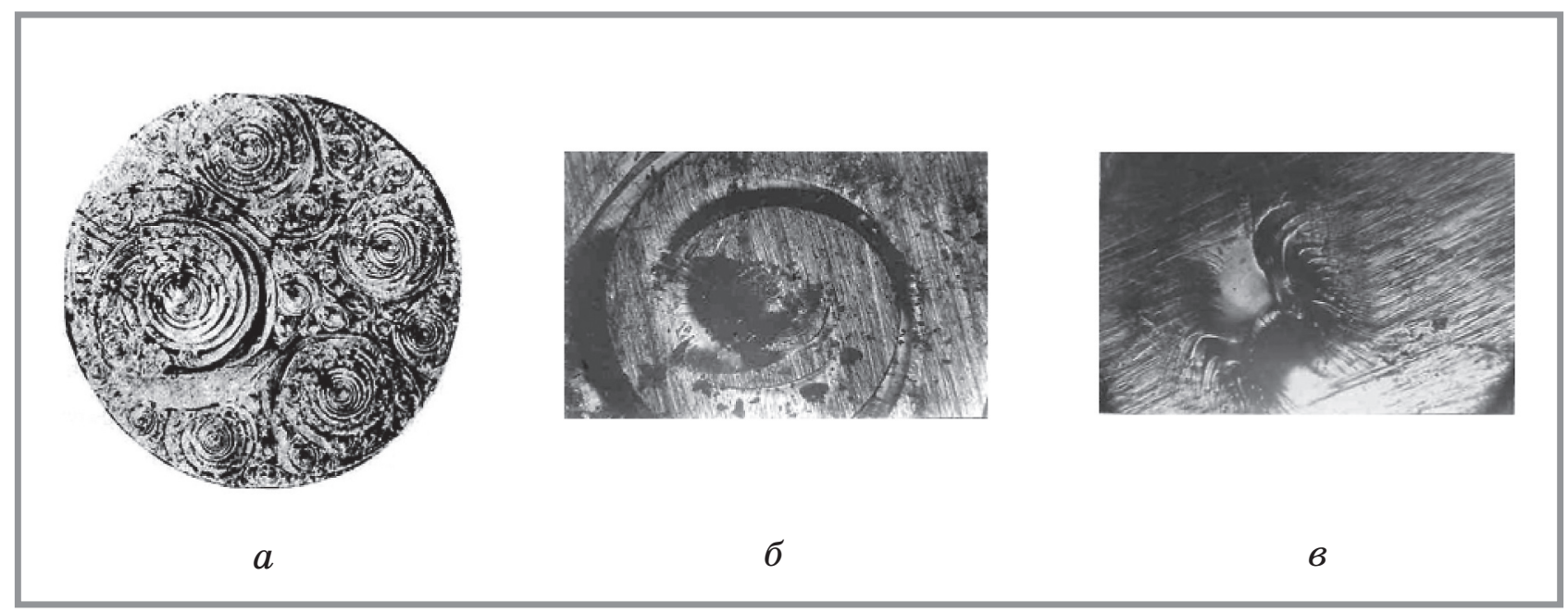

Рис. 2. Структуры в нефтяном пеке [16,18]:

a - зеренная структура (масштаб 1:1), б - дислокация роста (х32),

в - центр кристаллизации (х64) 
Оказывается, что парамагнетизм, сформированный на наноуровне, является управляющим параметром, запускающим механизм иерархического структурирования. Таким образом при контакте с поверхностью на ней через формирование наноуглерода происходит дислокационный рост кристаллического пека (спиралевидные образования).

Сильное взаимодействие молекул асфальтенов с металлической поверхностью препятствует диффузии отдельных атомов углерода. Повышенная температура и присутствие каталитической металлической поверхности приводит к самопроизвольному дегидрированию молекул асфальтенов, что приводит к формированию углеродных кластеров. Каждый атом в составе атомного кластера имеет меньше соседей, чем атом в объеме, что нарушает симметрию, координационные числа и приводит к сильной поляризации электронных оболочек. Поэтому для атомных кластеров устойчивыми оказываются конфигурации с осями симметрии 5-го порядка, недопустимыми для макрокристаллов. Такими стабильными кластерами являются фуллерены.

Сформировавшись, фуллерены изменяют распределение напряжений в поверхностном слое, приводят к его деформации, как бы «сдвигая» отдельные атомы верхнего слоя металла. Впервые такая способность фуллеренов «зарываться» в поверхностный слой металла была обнаружена на примере серебра [17].

С целью максимального формирования фуллеренов при науглероживании стальных образцов необходимо подобрать оптимальный температурный режим. Чем выше температура, тем меньшую роль играют адсорбционные и когезионные эффекты и большую роль начинают играть процессы деструкции полимерных углеродных структур. Снизу температура ограничена температурой размягчения нефтяного пека и перехода его в маловязкое состояние для улучшения подвижности молекул и возможности их диффузии к поверхности металла.

Науглероживание в среде нефтяного пека проводилось при темпеpaтуре $\mathrm{t}=360^{\circ} \mathrm{C}$ и времени выдержки в печи: 3 и 6 часов. При температуре $360^{\circ} \mathrm{C}$ углеродистая сталь имеет ферритную основу, обладающую низкой растворимостью углерода, поэтому для облегчения внедрения углерода вглубь металла и для интенсивного перемешивания атомов на границе пленка/подложка сталь переводилась в аустенитное состояние повышением температуры до $720^{\circ} \mathrm{C}$. Поскольку фуллерены и эндоэдральные фуллерены склонны к разрушению при повышенных 
температурах в условиях окружающей среды, то время диффузии ограничивали 30 минутами с дальнейшим резким охлаждением в воде.

Идентификация фуллеренов в поверхностном модифицированном слое производилась методами ИК-Фурье спектрометрии и высокоэффективной жидкостной хроматографии.

На рис. 3 представлены спектры образцов после науглероживания в среде пека и в среде карбоната бария, полученные на ИК-Фурье спектрометре.

$a$

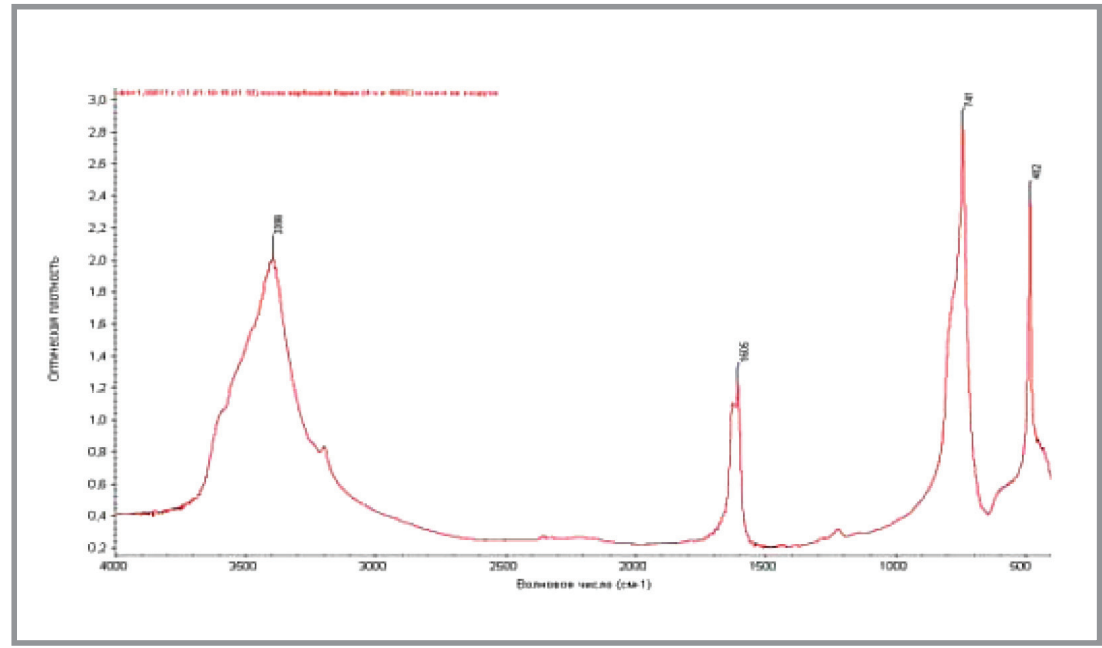

б

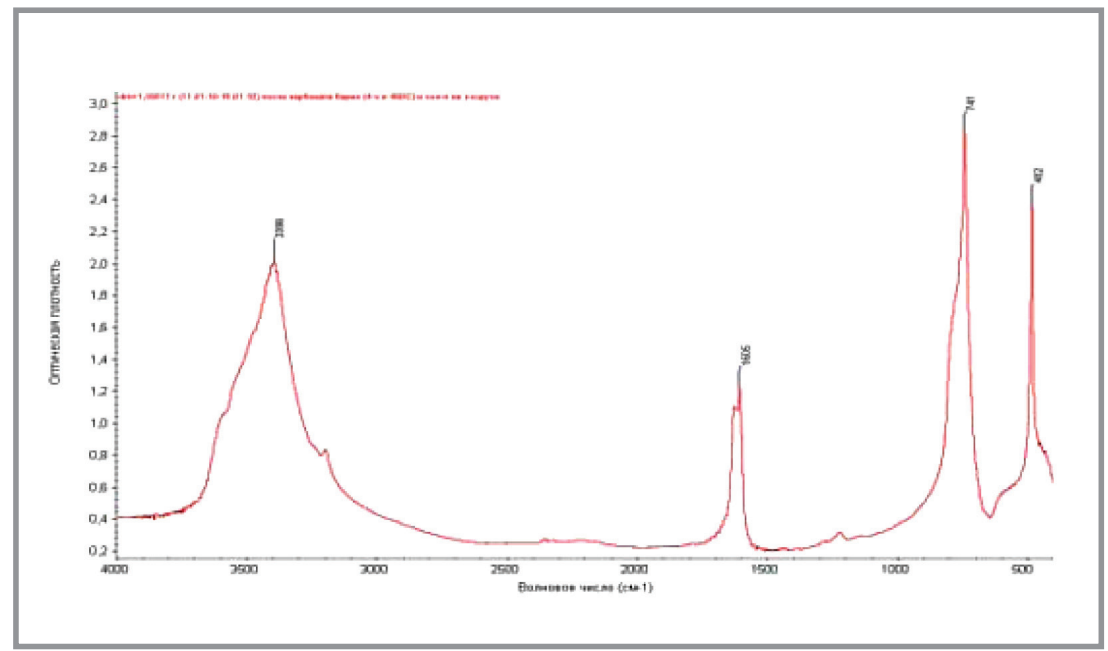

Рuc. 3. ИК спектры образцов фуллеренов $\mathrm{C}_{60}$ (a) и $\mathrm{C}_{70}$ (б) после обработки плавиковой кислотой, поверхностного науглероженного слоя стали 20 , полученного в среде пека (в) и в среде карбоната бария (г) 
Обнаружено, что образующиеся в ходе науглероживания в среде карбоната бария и в среде пека наноуглеродные структуры имеют различную морфологию. Об этом свидетельствует двойная полоса поглощения на частоте $1600 \mathrm{~cm}^{-1}$, соответствующая колебаниям связи $\mathrm{C}=\mathrm{O}$ при спектральном анализе поверхностного слоя образцов, полученных в среде карбоната бария, и более низкая реакционная способность образующихся в среде нефтяного пека наноуглеродных структур с кислородом воздуха. Сдвоенный пик на частоте поглощения, соответствующей колебаниям связи $\mathrm{C}=\mathrm{O}$, обусловлен наличием эндоэдральных фуллереновых комплексов. Таким образом, синтез углеродных нанотрубок на поверхности $\alpha-\mathrm{Fe}$ происходит через формирование эндоэдральных металлофуллеренов, которые описаны в ряде работ как карбиды переходных металлов.

Количественный анализ фуллереновых комплексов методом ИКФурье спектрометрии осуществлялся по интенсивности поглощения на частоте $482 \mathrm{~cm}^{-1}$. Методом ВЭЖ Х осуществлялся количественный анализ фуллеренов $\mathrm{C}_{60}$ и $\mathrm{C}_{70}$. Результаты представлены в табл. 1. Образцы растворялись в течение четырех суток в плавиковой кислоте. Образующийся осадок отфильтровывался, высушивался и измельчался. При растворении образца, науглероженного в среде $\mathrm{BaCO}_{3}$, образовалось 0,5 г порошка, а при растворении образца, полученного в среде нефтяного пека, образовалось 0,48 г порошка. Для снятия спектра на ИК-Фурье спектрометре использовалось 0,0005 г исследуемого порошка в бромиде калия. Для анализа методом ВЭЖХХ использовалось 1,5 г исследуемого порошка.

Такое различие в морфологии наноуглеродных структур объясняется различными механизмами формирования металлофуллеренового слоя из жидкой среды пека и среды карбонатов металлов. При науглероживании из среды карбонатов металлов определяющую роль при синтезе фуллеренов играет каталитическое действие поверхности с образованием эндоэдральных производных в поверхностном слое, в то время, как из среды пека фуллерены формируются при кристаллизации последнего, при этом центры кристаллизации имеют фуллереновую природу.

Анализ спектров указывает на правильность выбора технологических параметров процесса. При изменении условий науглероживания, как в среде пека, так и в среде карбоната бария, количественное содержание фуллереновых комплексов значительно уменьшается. 
Таблица 1

Концентрация фуллеренов $\mathrm{C}_{60}$ и $\mathrm{C}_{70}$ в растворе толуола

\begin{tabular}{|c|c|c|c|}
\hline Название образца & $\mathrm{C}_{60}$, мкГ/мл & $\mathrm{C}_{70}$, мкг/мл & $\begin{array}{l}\text { Фуллереновые } \\
\text { комплексы, \% }\end{array}$ \\
\hline Модифицированный в $\mathrm{BaCO}_{3}$ & не обнаружено & 0,275988 & $1,4 \%$ \\
\hline $\begin{array}{l}\text { Модифицированный в } \mathrm{BaCO}_{3} \\
\text { без температурного скачка }\end{array}$ & не обнаружено & 0,130392 & $0,1 \%$ \\
\hline $\begin{array}{l}\text { Модифицированный в нефтя- } \\
\text { ном пеке при } 360^{\circ} \mathrm{C} \tau=3 \text { часа }\end{array}$ & 1,234543 & 0,2764165 & $1,4 \%$ \\
\hline $\begin{array}{l}\text { Модифицированный в нефтя- } \\
\text { ном пеке при } 360^{\circ} \mathrm{C} \tau=6 \text { часов }\end{array}$ & 0,132348 & 0,1162123 & $0,9 \%$ \\
\hline $\begin{array}{l}\text { Модифицирование при } 420^{\circ} \mathrm{C} \\
\text { в среде пека }\end{array}$ & 0,090348 & 0,100545 & $0,2 \%$ \\
\hline
\end{tabular}

Анализ хроматограмм, полученных при длине волны 330 нм, свидетельствует в пользу формирования наноуглеродных структур различной морфологии. Время удерживания в ходе хроматографического анализа определяется массой наноуглеродной структуры. Следует отметить, что при науглероживании в среде карбоната бария без температурного скачка пики выходят до выхода пика толуола. Полученный результат косвенно свидетельствует в пользу формирования фуллеренов $\mathrm{C}_{\mathrm{n}}$ c n $<60$ при проведении процесса без температурного скачка. На хроматограмме образца, полученного в среде карбоната бария с температурным скачком, снятой при длине волны 330 нм, наблюдается несколько пиков после выхода толуола, что косвенно свидетельствует в пользу наличия эндометаллофуллеренов в поверхностном слое.

Таким образом, руководствуясь теоретическими данными и данными спектрального и хроматографического анализа, установлены оптимальные условия формирования металлофуллеренового слоя в среде карбоната бария и нефтяного пека.

При визуальном осмотре науглероженных образцов в среде карбоната бария и пека обнаружено, что поверхностный слой образцов из стали 20 имеет гладкую поверхность без шероховатостей, что указывает на низкую пористость металлофуллеренового слоя и что обусловлено 
увеличением силы сцепления кристаллитов между собой (аналогичные эксперименты были проведены на образцах из стали ШХ15). Напротив, при изменении условий науглероживания поверхность становится шероховатой. Шероховатость формируется образующимися дефектами в поверхностном слое, возникающими при науглероживании.

По результатам растровой электронной микроскопии металлофуллереновый слой, полученный в среде карбоната бария, имеет толщину 125 мкм, металлофуллереновый слой, полученный в среде пека, имеет толщину 193 мкм.

Формирование металлофуллеренового поверхностного слоя приводит к значительному уменьшению среднего размера кристаллических зерен. Малый размер зерен (менее 100 нм) обусловливает большую развитость и протяженность межзеренных границ. Кроме того, сами зерна размером менее 100 нм практически свободны от дефектов - дисклинаций и дислокаций, что качественно отличает нанокристаллические материалы от материалов с крупным зерном.

Исследовалась твердость полученных металлофуллереновых слоев с помощью микротвердомера МНT-100 при двух нагрузках - 25 грамм и 50 грамм. Скорость нагружения составляла 5 г/с, время нагружения 5 секунд. Для замера микротвердости выбиралась определенная локальная область поверхности и осуществлялось десять параллельных замеров микротвердости для повышения точности полученного значения.

Результаты измерения микротвердости стали 20 до и после модифицирования занесены в табл. 2 .

Произведено определение прочности сцепления металлофуллеренового слоя с металлической основой при испытаниях на трехточечный изгиб по ГОСТ 14019-2003. Испытанию были подвержены прямоугольные образцы из стали 20 с модифицированным поверхностным слоем, размерами $80 \times 6 \times 4$ мм.

После установки образцов на захваты используемой машины задавался ход траверсы для изгиба исследуемого образца. В течение всего процесса деформирования производили наблюдение за процессом изгиба с целью фиксации возможного разрушения поверхностного слоя. Ход траверсы позволяет получить угол сгиба образца $\alpha=9^{\circ}$.

В результате деформирования при угле изгиба, равном $12^{\circ}$, произошло отслоение науглероженного слоя, полученного в среде карбоната бария с поверхности образца. 
Таблица 2

\section{Результаты измерения микротвердости}

\begin{tabular}{|c|l|c|}
\hline $\begin{array}{c}\text { Нагрузка, } \\
\text { грамм }\end{array}$ & \multicolumn{1}{|c|}{ Образец } & Микротвердость HV HV \\
\hline \multirow{3}{*}{25} & Без модифицирования & $265,5 \pm 7,08$ \\
\cline { 2 - 3 } & С модифицированием в среде $\mathrm{BaCO}_{3}$ & $344 \pm 21$ \\
\cline { 2 - 3 } & $\begin{array}{l}\text { С модифицированием в среде } \\
\text { нефтяного пека }\end{array}$ & $206,3 \pm 24,7$ \\
\hline \multirow{3}{*}{50} & Без модифицирования & $233,15 \pm 15,9$ \\
\cline { 2 - 3 } & С модифицированием в среде $\mathrm{BaCO}_{3}$ & $295,6 \pm 16,6$ \\
\cline { 2 - 3 } & $\begin{array}{l}\text { С модифицированием в среде } \\
\text { нефтяного пека }\end{array}$ & $217,8 \pm 24,3$ \\
\hline
\end{tabular}

Слабое сцепление модифицированного в среде карбоната бария слоя с металлической основой вызвано ограниченной диффузией углерода в объеме $\alpha-\mathrm{Fe}$. Согласно выявленному механизму формирования фуллеренов в газовой среде на поверхности стали, фуллерены формируются на каталитических центрах - атомах железа, образуя тонкий металлофуллереновый слой, обладающий низкой дефектностью. Дальнейшее увеличение толщины модифицированного слоя должно было неизбежно привести к его полному отслаиванию, что и наблюдалось в процессе испытаний.

Противоположная картина наблюдается при исследовании прочности сцепления науглероженного слоя, полученной в среде нефтяного пека, с металлической подложкой. В результате проведенных испытаний при изгибе на угол $\alpha=90^{\circ}$ обнаружена высокая прочность сцепления науглероженного слоя с металлической матрицей. Полученный результат свидетельствует о диффузии углерода вглубь металла и его равномерном распределении в железной матрице. При деформации науглероженных образцов науглероженный слой не потерял свою целостность, при этом не обнаружились признаки хрупкого разрушения. Следовательно, полученный металлофуллереновый слой не имеет четкой границы фаз со структурой основного металла и является продолжением матрицы металла. 
Уменьшение микротвердости образцов с металлофуллереновым поверхностным слоем, полученным в среде нефтяного пека, по сравнению со значением микротвердости образцов без науглероживания обусловлено уменьшением размера зерна до критического значения $\mathrm{d} \sim 10 \mathrm{Hм}$ при образовании в нем фуллеренов. Увеличение микротвердости образцов с металлофуллереновым слоем, полученным в среде карбоната бария, обусловлено низкой адгезионной прочностью его с поверхностью металла, в результате чего он фактически выступает как тонкое фуллереновое покрытие.

Таким образом, комплексные исследования диффузии углерода в сталь из органической и неорганической среды показали различия механизмов формирования металлофуллеренового слоя и позволили разработать эффективные алгоритмы технологии модифицирования поверхности.

Исследования проводятся в Уфимском государственном нефтяном техническом университете в рамках реализации инициативного научного проекта фундаментального характера по государственному заданию образовательным учреждениям высшего образования на 2017-2019 гг. (№ 9.7294.2017/8.9 от 31.01.2017) при содействии Межвузовского центра коллективного пользования «Региональный научно-производственный комплекс “Недра”".

\section{Библиографический список:}

1. Чиркова А.Г., Хаерланамова Е.А., Кузеев И.Р. Образование квазимногослойных оболочек при эксплуатации труб змеевика печи пиролиза углеводородов // Mеханика композиционных материалов и конструкций. -2004 . - Том 10 , № 2. C. $153-165$.

2. Kuzeev I.R., Popova S.V., Fazlyakhmetov R.F. Wear resistance of steel 20 after thermochemical treatment in fluid petroleum pitch // Journal of Friction and Wear. - 2011. - T. 32, № 3. - C. 186-191.

3. Габдуллина М.Р., Кузеев И.Р., Никифорова Д.К., Габдуллин М.Ф. Формирование металлофуллеренового поверхностного слоя с целью пассивации поверхности в углеродных сталях // Нефтегазовое дело. - 2014. - № 3. - С. 310-328. 
4. Степанюк O.B. Теоретическое исследование процессов формирования и физических свойств наностуруктур на поверхности: дис. кан. физико-математич. наук. - Москва, 2010. - 25 с.

5. Золотухин A.A. Формирование углеродных пленок из газовой фазы: дис. на соискание ученой степени канд. физико-математич. наук. - Москва, 2007. - 25 с.

6. Корнеева Ю.В. Структурные превращения в металлических частицах катализаторов в различных процессах синтеза УНТ: дис. канд. физико-математич. наук. - Москва, 2008. - 22 с.

7. Мутигуллин И.В. Особенности взаимодействия атомов углерода на поверхности и в объеме монокристаллов $\mathrm{Fe}, \mathrm{Ni}$ и сплавов на их основе: дис. канд. физико-математич. наук. - Москва, 2010. - 23 с.

8. Арзаласов Б.Н. Справочник по конструкционным материалам. - Москва: МГТУ им. Н.Э. Баумана, 2005. - 640 с.

9. Киселева Т.Ю., Новикова А.А., Тарасов Б.П., Мурадян В.С., Володин А.А. Диагностика продуктов электродугового синтеза углеродных нанотрубок на катализаторах $\mathrm{Fe}$ и $\mathrm{Fe}-\mathrm{Ni}$ методом мессбауэровской спектроскопии // Сборник тезисов докладов 1-ой Международной конференции «Углерод: фундаментальные проблемы науки, материаловедение, технология». - Москва, 2002. - С. 110.

10. Кудашов А.Г., Окотруб Л.В., Юданов И.Ф., Гусельников Л.В., Абросилов О.Т., Шубин Ю.В. Каталитический синтез углеродных нанотрубок // Сборник тезисов докладов 1-ой Международной конференции «Углерод: фундаментальные проблемы науки, материаловедение, технология». - Москва, 2002. - С. 124.

11. Щур Д.В., Матысина З.А., Загинайченко С.Ю. Взаимодействие углерод-катализатор при синтезе углеродных нанотрубок // 1-ая Международная конференция «Углерод: фундаментальные проблемы науки, материаловедение, технология». - Москва, 2002. - С. 141.

12. Караева А.Р., Долгова Е.А., Харитонов Д.Н., Маслов И.А., Каленев А.А., Третьяков В.Ф., Мордкович В.З. Активность Ni и Fе в синтезе наноуглерода при каталитической конверсии метана // Российский химический журнал. - 2006. Tом L, № 1. - C. 64-67.

13. Кузеев И.Р., Попова С.В., Васильев А.Н., Шелагонова Е.В. Углерод в структуре железной матрицы и его влияние на эксплуатационные свойства конструкционных сталей // Управление качеством в нефтегазовом деле. - 2010. - Том 2, № 2. - С. 30-33.

14. Корнеева Ю.В. Структурные превращения в металлических частицах катализаторов в различных процессах синтеза углеродных нанотрубок: дис. канд. физико-математич. наук. - Москва, 2008. - 22 с. 
15. Сидоров Л.Н., Юровская М.А., Борщевский А.Я. и др. Фуллерены. - Москва: Изд. Экзамен, 2005. - 688 с.

16. Кузеев И.Р. Совершенствование технологии и повышение долговечности реакционных аппаратов термодеструктивных процессов переработки углеводородного сырья: дисс. д-ра технич. наук. - Уфа, УНИ, 1987. - 427 с.

17. Y.I. Li. Surface Geometry of C60 on Ag(111) / Y.I. Li, K. Pussi, K.J. Hanna, L.-L. Wang, D.D. Johnson, H.-P. Cheng, H. Shin, S. Curtarolo, W. Moritz, J.A. Smerdon, R. McGrath and R.D. Diehl // PHYSICAL REVIEW LETTERS PRL. 103. 056101 (2009).

18. Гафарова B.A. Углерод в конденсированных углеводородных фазах, сталях и чугунах // Нанотехнологии в строительстве. - 2017. - Том 9, № 6. - С. 111128. - DOI: dx.doi.org/10.15828/2075-8545-2017-9-6-111-128.

19. Демченко М.В., Сисанбаев А.В., Кузеев И.Р. Исследования состояния сварного соединения металла по параметрам деформационного и коррозионного рельефа поверхности // Нанотехнологии в строительстве. - 2017. - Том 9, № 5. C. 98-115. - DOI: dx.doi.org/10.15828/2075-8545-2017-9-5-98-115.

20. Кузеев И.Р. Идентификации фуллеренов в структуре железоуглеродистых сплавов // Нанотехнологии в строительстве. - 2017. - Том 9, № 6. - С. 151163. - DOI: dx.doi.org/10.15828/2075-8545-2017-9-6-151-163.

\section{УВАЖАЕМЫЕ КОЛЛЕГИ!}

ПРИ ИСПОЛЬЗОВАНИИ МАТЕРИАЛА ДАННОЙ СТАТЬИ

ПРОСИМ ДЕЛАТЬ БИБЛИОГРАФИЧЕСКУЮ ССЫЛКУ НА НЕЁ:

Кузеев И.Р., Попова С.В., Абызгильдина С.Ш. Получение металлофуллеренового поверхностного слоя при науглероживании стали из различных сред // Нанотехнологии в строительстве. - 2018. - Том 10, № 2. - C. 135-152. - DOI: dx.doi.org/10.15828/2075-8545-2018-10-2-135-152.

\section{DeAR COLleagues!}

THE REFERENCE TO THIS PAPER HAS THE FOLLOWING CITATION FORMAT:

Kuzeev I.R, Popova S.V., Abyzgildina S.Sh. Production of metal fullerene surface layer from various media in the process of steel carbonization. Nanotehnologii $\mathrm{v}$ stroitel'stve $=$ Nanotechnologies in Construction. 2018, Vol. 10, no. 2, pp. 135152. DOI: dx.doi.org/10.15828/2075-8545-2018-10-2-135-152. (In Russian). 